\title{
NUDTI5 c.4I5C>T Polymorphism Predicts 6-MP Induced Early Myelotoxicity in Patients with Acute Lymphoblastic Leukemia Undergoing Maintenance Therapy
}

\author{
Aswin Anand Pai \\ Ajith Mohan (D) \\ Esther Sathya Bama Benjamin \\ Raveen Stephen Stallon \\ Illangeswaran \\ Infencia Xavier Raj \\ Nancy Beryl Janet \\ Arun Kumar Arunachalam (D) \\ ML Kavitha \\ Uday Kulkarni \\ Anup J Devasia \\ NA Fouzia \\ Aby Abraham \\ Alok Srivastava \\ Biju George \\ Vikram Mathews \\ Anu Korula \\ Poonkuzhali Balasubramanian (D)
}

Department of Haematology, Christian Medical College, Vellore, Tamilnadu, India

Correspondence: Poonkuzhali

Balasubramanian

Department of Haematology, Christian

Medical College, Vellore, Tamilnadu, India

Email bpoonkuzhali@cmcvellore.ac.in
Purpose: Severe myelosuppression in patients with acute lymphoblastic leukemia (ALL) undergoing 6-MP-based maintenance therapy is attributed to TPMT gene polymorphisms, which is rare in Asian populations. This study aims to evaluate the role of selected polymorphisms in NUDT15, ITPA, and MRP4 genes in addition to TPMT in predicting 6-MP intolerance during ALL maintenance therapy.

Patients and Methods: We screened for the presence of $N U D T 15 * 3$ (c.415 $\mathrm{C}>\mathrm{T}$, rs116855232); MRP4 c.2269 C > T (rs3765534), ITPA c.94 C $>$ A (rs1127354) polymorphisms in addition to TPMT *2 (rs1800462), *3A (*3B and *3C; rs1800460 and rs1142345) in ALL patients with documented severe neutropenia (cohort-1; $\mathrm{n}=42$ ). These polymorphisms were then screened in a prospective cohort of ALL patients (cohort-2; $n=133$ ) and compared with 6-MP dose reduction, early/late myelotoxicity.

Results: Nineteen (45\%) patients in cohort-1 and 18 (14\%) in cohort-2 had NUDT15 c. 415 C $>$ T variant while $4(3 \%)$ patients in cohort-2 had TPMT*3C variant. Five $(12 \%)$ in cohort-1 and 30 $(24 \%)$ in cohort-2 had ITPA c.94 C>A variant while $9(22 \%)$ and $15(12 \%)$ had MRP4 c.2269 $\mathrm{C}>\mathrm{T}$ variant in cohorts-1 and 2, respectively. All in cohort-1 and $36(27 \%)$ in cohort-2 had severe myelotoxicity. Twenty-eight patients $(66.6 \%)$ in cohort-1 and $40(30 \%)$ patients in cohort-2 had significant 6-MP dose reduction. NUDT15 c.415 C $>$ T variant explained severe myelotoxicity in $63 \%$ and $33 \%$ in cohort 1 and 2. TPMT*3C and ITPA c.94 $\mathrm{C}>\mathrm{A}$ variants also explained myelotoxicity in cohort-2 (Median ANC: $376 \mathrm{vs} 1014 \mathrm{~mm}^{3}$; p=0.04 and $776 \mathrm{vs} 1023 \mathrm{~mm}^{3}$; $\mathrm{p}=0.04$ respectively). NUDT15 c. $415 \mathrm{C}>\mathrm{T}$ polymorphism explained significant myelotoxicity (507 vs $\left.1298 \mathrm{~mm}^{3} ; \mathrm{p}<0.0001\right)$ in the multivariate analysis as well $(\beta=-0.314, \mathrm{p}<0.0001)$.

Conclusion: NUDT15 c.415 C>T $\left(15^{*} 3\right)$, TPMT*3C, as well as ITPA c.94 C>A and MRP4 c.2269 $\mathrm{C}>\mathrm{T}$ polymorphisms explain hematotoxicities. Preemptive genotype-based (NUDT15*3, TPMT, ITPA c.94 C>A) 6-MP dosing could improve the outcome after maintenance therapy.

Keywords: leukemia, mercaptopurine, myelotoxicity, pharmacogenomics

\section{Introduction}

Acute lymphoblastic leukemia (ALL) is the most common childhood cancer and also occurs in adults. ${ }^{1}$ The last phase of the treatment of ALL involves maintenance therapy with daily oral 6-mercaptopurine (6-MP) and weekly methotrexate (MTX) for nearly 2 years in most treatment protocols. However, the significant doselimiting toxicity is life-threatening myelosuppression ${ }^{2}$ owing to the narrow 
therapeutic indices of these drugs and a wide interindividual variation in drug response. These toxicities often lead to extended hospitalization resulting in increased cost of treatment. Genetic polymorphisms in drug-metabolizing enzymes and transporters contribute significantly to this variability in response to drugs. It is now well acknowledged that polymorphisms in Thiopurine Methyltransferase (TPMT) ${ }^{3}$ and Nucleoside diphosphatelinked moiety X-type motif $15(N U D T 15)^{4-6}$ genes explain 6-MP mediated cytopenia.

We have reported previously that TPMT variants are rare in our population and do not fully explain the severe myelosuppression occurring in patients with ALL undergoing maintenance therapy. ${ }^{7}$ Further screening for NUDT15 c.415 C>T polymorphism in a cohort of patients with severe myelosuppression (but lacking TPMT variants) showed that only $\sim 53 \%$ of these patients carried NUDT15 c. $415 \mathrm{C}>\mathrm{T}^{8}$ suggesting that additional genetic factors could play a role. Polymorphisms in Multidrug resistance protein-4 (MRP4 c.2269 C>T) ${ }^{9,10}$ and Inosine triphosphate pyrophosphatase (ITPA c. $94 \mathrm{C}>\mathrm{A}$ ) ${ }^{11-13}$ have also been shown to explain toxicity to 6-MP in specific ethnic populations. We have previously reported that TPMT polymorphisms are rare in our populations and do not entirely explain the variation in 6-MP toxicity. ${ }^{7}$ We have recently reported that NUDT15 c.415C>T polymorphism is a significant determinant of myelosuppression related to the intake of thiopurines in patients with Immune thrombocytopenic purpura and autoimmune hemolytic anemia. ${ }^{14} \mathrm{~A}$ recent report from the Clinical Pharmacogenetics Implementation Consortium (CPIC) has recommended preemptive genotyping of NUDT15 apart from TPMT variant testing before 6-MP dosing. ${ }^{6}$

Although previous studies in the Indian population have highlighted the role of NUDT15 c.415 $C>T$ polymorphism associated with 6-MP toxicity, ${ }^{15-17}$ there are no comprehensive reports on all the identified genetic polymorphisms related to 6-MP intolerance and early hematological toxicities in patients with ALL. This study aims to evaluate the role of selected polymorphisms in ITPA, and MRP4 genes in addition to CPIC recommended NUDT15 and TPMT testing in predicting 6-MP intolerance/6-MP dose reduction and toxicities during ALL maintenance therapy.

\section{Patients and Methods}

\section{Patients}

Patients with ALL who experienced severe clinical thiopurine-related myelotoxicity requiring dose-reduction referred for TPMT genetic testing from 2009 to 2017 were included (cohort-1). In addition, all consecutive patients diagnosed with ALL undergoing maintenance therapy between September 2018 and March 2020 in the Department of Hematology, Christian Medical College, Vellore, India, were prospectively enrolled (Cohort-2). The purpose of retrospective cohort 1 is to identify genetic polymorphisms (in addition to TPMT) that could explain myelotoxicity, while prospective cohort-2 is to study the influence of genetic polymorphisms on 6-MP intolerance, toxicities, and survival. Patients with less than six-month follow-up or lost follow-up, who underwent consolidation therapy with 6-MP, and those who refused to consent, were excluded from the analysis. Written informed consent was obtained from the patients/parents. This study was approved by the Institutional Review Board [IRB (EC)-ER-1-23-07-2014]. The initial doses of 6-MP and MTX for maintenance therapy were $50 \mathrm{mg} / \mathrm{m}^{2}$ daily and $20 \mathrm{mg} / \mathrm{m}^{2}$ weekly, respectively. The treating physicians adjusted the 6-MP/MTX doses to maintain a white blood cell (WBC) count of $3.0 \times 10^{9} / \mathrm{L}$ and avoid infections and hepatotoxicity.

\section{Genotyping}

Before starting maintenance therapy, peripheral blood was collected in EDTA tubes, and DNA was extracted using the Qiagen Gentra kit. The samples were screened for selected polymorphisms: NUDT15*3 (c.415 C > T, rs116855232, p. Arg139Cys), ITPA (c.94 C > A, rs1127354, p.Pro32Thr) and MRP4 (c.2269 G>A, rs3765534, p.Glu757Lys) by bidirectional sanger sequencing ${ }^{14}$ and $T P M T * 3 \mathrm{~A}[* 3 \mathrm{~B}(460 \mathrm{G}>\mathrm{A}$, rs1800460, p.Ala154Thr) and *3C (719 A > G, rs1142345, p. Tyr240Cys)] by Restriction Fragment Length Polymorphism (RFLP) and [*2(238G >C, rs1800462, p.Ala80Pro)] by PCR using allele-specific oligonucleotides (ASO) as reported previously. ${ }^{7}$ Additionally, polymorphisms in NUDT15 exon1 were screened by Sanger sequencing as reported previously. ${ }^{18}$

\section{Clinical Outcomes}

Clinical data such as dose reduction, WBC/ANC counts, and ALT/AST levels were monitored and documented longitudinally throughout the maintenance therapy. \%6-MP dose intensity was defined as the ratio between clinician prescribed 6-MP dose to protocol dose (\%) and was captured monthly for the first 6-months since the start of 6-MP. We calculated the average 6-MP dose intensity (up to 6 months) for association analysis in the present study. In addition, information on the total direct hospital costs incurred during the first 6 months of 
maintenance therapy was obtained for all the patients. Therapy interruption was defined as the cessation of medicine administration resulting from cytopenia, infections, or hepatotoxicity. Hepatotoxicity (Grade 3 and above) was defined based on the Common Terminology Criteria for Adverse Events version 5.0) $\left(\right.$ CTCAE5.0) ${ }^{19}$ (ALT/AST levels $>5.0-20.0 \times$ ULN if the baseline was normal; $>5.0-20.0 \times$ baseline if the baseline was abnormal at any time point during maintenance therapy). Severe myelotoxicity/neutropenia was defined as ANC (Absolute Neutrophil Count) below 500/ $\mathrm{mm}^{3}$. Early and late myelotoxicity were documented during 1-3 and 4-6 months, respectively, after maintenance therapy. Overall survival (OS) was calculated from the start of maintenance therapy to the date of death or the last follow-up as applicable. Event Free Survival (EFS) was defined as the percentage of patients who were alive without relapse or death at last follow-up through maintenance therapy. Relapse Free Survival (RFS) was defined as the percentage of patients who had no relapse event at last follow-up from the start of maintenance therapy. Relapse and survival were documented for the prospective cohort only.

\section{Statistics}

All statistical analyses were performed using SPSS (IBM SPSS statistics version 21.0, Armonk, NY) and GraphPad Prism 8 (GraphPad Software, La Jolla, CA); p-value $<0.05$ was used for significance testing. Comparison of clinical response indices such as myelotoxicity (ANC), leukotoxicity (WBC), hepatotoxicity (ALT/AST levels), and \%6-MP dose intensities with genotype was done using one-way ANOVA or Mann-Whitney $U$-test. Associations between genotypes and clinical responses were evaluated using a linear regression model, and multivariate analysis was performed with significant covariates from univariate linear regression model. Haplotype analyses for all genes were performed using SNPStats programs (Institut Català d'Oncologia, Barcelona, Spain). We used Firth logistic regression to test the association between polymorphism and outcomes ( $R$ Statistical software version 4.0.3; $\mathrm{R}$ Foundation for Statistical Computing, Vienna, Austria). Log-rank Cox regression was used for the survival analysis, and the Kaplan-Meier curves were generated for OS, EFS, and RFS.

\section{Results}

\section{Patient Demographics}

The baseline characteristics of patients included in cohort$1(\mathrm{n}=42)$ are listed in Table 1 . During the study period, 241 patients with ALL underwent maintenance therapy in our center. Of these, patients who gave consent to participate in the study and those with regular follow-up were prospectively enrolled (cohort- $2 ; n=133$ ). The study design is illustrated in Figure 1. There was no significant difference in demographics between the patients enrolled in the study and those not enrolled (Table S1). Most of the patients had B-ALL (82.5\%) and belonged to intermediate cytogenetic risk $(58 \%)$ based on stratification reported previously. ${ }^{20,21}$

\section{Genotype}

None of the patients carried TPMT polymorphisms in cohort1 , while four patients $(3 \%)$ were heterozygous for the $T_{P M T}^{*} 3 \mathrm{C}$ variant in cohort-2. Nineteen patients in cohort-1 had NUDT15 c.415C>T variant (14 heterozygous and five homozygous), while 18 in cohort- 2 were heterozygous for this variant. None of the patients included in the study had polymorphisms in exon 1 of the NUDT15 gene. The allelic and genotypic frequencies are tabulated in Table S2.

\section{6-MP Dose}

In cohort-1, eight patients (19\%) required drastic 6-MP/ MTX dose reduction (less than 50\%), 20 (47.6\%) received $50-80 \%$ of the total dose, and $14(33.4 \%)$ received more than $80 \%$ of the planned dose of $6-\mathrm{MP}$.

The majority of the patients in cohort- $2(n=93 ; 70 \%)$ received more than $80 \%$ of the planned dose while $36(27 \%)$ received $50-80 \%$ of the full dose, and four $(3 \%)$ patients received less than $50 \%$ of the total planned dose of $6-\mathrm{MP}$.

\section{Incidence of Myelotoxicity and Hepatotoxicity}

Although all the 42 patients in cohort-1 had severe myelotoxicity, 16 patients $(38 \%)$ had severe neutropenic episodes [median ANC $<500$ (range $32-504 / \mathrm{mm}^{3}$ )], while remaining $26(62 \%)$ had a median ANC of 1100 (range: 528-1760/ $\mathrm{mm}^{3}$ ) during the study period. Three patients $(7 \%)$ had a high ALT level (Grade 3), and one patient (2\%) had a high AST level (Grade 3) based on NCI CTCAE criteria.

Thirty-six patients $(27 \%)$ in cohort-2 had severe neutropenic episodes [median ANC $<500$ (range: $36-507 / \mathrm{mm}^{3}$ )]. Twelve patients (9\%) had high ALT levels (Grade 3), and two patients (2\%) had high AST levels (Grade 3 ).

Further outcome analysis was carried out only in cohort-2, where 21 patients $(16 \%)$ relapsed during or after maintenance therapy, and the 3-year RFS in this cohort was $84.2 \%$ at a median follow-up of 18 (6-38) months. One hundred and twenty-eight patients were 
Table I Baseline Characteristics of Patients

\begin{tabular}{|c|c|c|}
\hline Patient Parameters & $\begin{array}{c}\text { Cohort-I } \\
(n=42) N(\%)\end{array}$ & $\begin{array}{c}\text { Cohort-2 } \\
(n=133) \text { N (\%) }\end{array}$ \\
\hline $\begin{array}{l}\text { Median Age at } \\
\text { Diagnosis (range) }\end{array}$ & $16.5(2-56)$ & $17(I-63)$ \\
\hline $\begin{array}{l}\text { Sex } \\
\qquad \text { Male } \\
\text { Female }\end{array}$ & $\begin{array}{l}35(83.3) \\
07(16.7)\end{array}$ & $\begin{array}{l}88(66) \\
45(34)\end{array}$ \\
\hline $\operatorname{BSA}\left(\mathrm{m}^{2}\right)$ & $1.5(0.5-2.2)$ & $1.5(0.4-2.1)$ \\
\hline $\begin{array}{l}\text { Immunophenotype } \\
\text { B cell } \\
\text { T cell } \\
\text { MP-ALL } \\
\text { NA }\end{array}$ & $\begin{array}{c}31(73.8) \\
09(21.4) \\
- \\
2(4.7)\end{array}$ & $\begin{array}{l}\text { II I }(83.4) \\
20(15) \\
\text { I }(I) \\
\text { I }(I)\end{array}$ \\
\hline $\begin{array}{l}\text { Cytogenetics Risk } \\
\text { Favourable } \\
\text { Intermediate } \\
\text { Poor } \\
\text { NA }\end{array}$ & $\begin{array}{c}6(14.2) \\
25(59.5) \\
7(16.7) \\
4(9.6)\end{array}$ & $\begin{array}{l}25(18.7) \\
81(61) \\
7(5.3) \\
20(15)\end{array}$ \\
\hline $\begin{array}{l}\text { ALL Risk } \\
\text { Standard Risk } \\
\text { Intermediate Risk } \\
\text { High Risk } \\
\text { NA }\end{array}$ & $\begin{array}{c}17(40.4) \\
20(47.6) \\
5(12) \\
-\end{array}$ & $\begin{array}{c}20(15) \\
70(52.6) \\
5(3.8) \\
38(28.6)\end{array}$ \\
\hline $\begin{array}{l}\text { Polymorphisms } \\
\text { TPMT variants } \\
\text { *2A } \\
\text { Homozygous reference } \\
\text { Not available }\end{array}$ & $\begin{array}{c}42(100) \\
0\end{array}$ & $\begin{array}{c}130(100) \\
3(-)\end{array}$ \\
\hline $\begin{array}{l}\text { *3A }(* 3 \mathbf{B} \& \mathbf{C}) \\
\text { Homozygous reference } \\
\text { Heterozygous variant } \\
\text { Not available }\end{array}$ & $\begin{array}{c}39(100) \\
- \\
3(-)\end{array}$ & $\begin{array}{c}123(96.8) \\
4(3.2) \\
6(-)\end{array}$ \\
\hline $\begin{array}{l}\text { ITPA c.94 C > A } \\
\text { Homozygous reference } \\
\text { Heterozygous variant } \\
\text { Homozygous variant } \\
\text { Not available }\end{array}$ & $\begin{array}{c}37(88) \\
5(12) \\
- \\
-\end{array}$ & $\begin{array}{c}97(76.4) \\
28(22) \\
2(1.6) \\
6(-)\end{array}$ \\
\hline $\begin{array}{l}\text { MRP4 c.2269G>A } \\
\text { Homozygous reference } \\
\text { Heterozygous variant } \\
\text { Homozygous variant } \\
\text { Not available }\end{array}$ & $\begin{array}{c}32(76.2) \\
9(21.4) \\
\text { । }(2.4) \\
-\end{array}$ & $\begin{array}{c}107(80) \\
13(10) \\
2(2) \\
11(8)\end{array}$ \\
\hline $\begin{array}{c}\text { NUDTI5 c.4I 5C>T } \\
\text { Homozygous reference } \\
\text { Heterozygous variant } \\
\text { Homozygous variant }\end{array}$ & $\begin{array}{c}23(54.7) \\
14(33.3) \\
5(12)\end{array}$ & $\begin{array}{c}115(86) \\
18(14) \\
-\end{array}$ \\
\hline
\end{tabular}

alive at the time of the last follow-up. The 3-year OS and EFS were 96.2 and $83.5 \%$, respectively, at a median follow-up of 18 (6-38) months.

\section{NUDT I5, TPMT, ITPA, MRP4 Polymorphisms, and 6-MP Dose Reduction/Therapy Intervention Cohort-I}

Although all the patients in cohort-1 had neutropenic episodes and required dose reduction, the NUDT15 c.415C >T was identified only in 19 patients and ITPA c. $94 \mathrm{C}>\mathrm{A}$ in 3 and MRP4 c.2269G>A in 2 patients, respectively. While five patients homozygous for NUDT15 c.415C $>\mathrm{T}$ polymorphism were highly sensitive to 6-MP and tolerated only $25 \%$ of the median dose intensity (range $14-34 \%$ of the protocol dose), those with heterozygous $(n=14)$ or wild-type genotype $(n=23)$, tolerated an average dose intensity of $58 \%(31-94)$ and $77 \%$ (46-96), $p=0.040$ and 0.0005 , respectively (Figure $2 \mathrm{~A}$ ).

With respect to therapy intervention, patients in cohort-1 who were homozygous for NUDT15 $\mathrm{c} .415 \mathrm{C}>\mathrm{T}$ polymorphism had the maximum duration of cessation of 6-MP therapy [median: 80 (25-94) days] compared to patients who were heterozygous or wild type [21 (7-54) and 28 (7-70) days, $\mathrm{p}=0.080$ and 0.009 , respectively] (Figure 2B).

\section{Cohort-2}

None of the patients in cohort-2 were homozygous for NUDT15 c. $415 \mathrm{C}>\mathrm{T}$ polymorphism. Patients heterozygous $(\mathrm{n}=18(14 \%))$ for $N U D T 15$ c. $415 \mathrm{C}>\mathrm{T}$ polymorphism were sensitive to 6-MP compared to those with wild type $(\mathrm{n}=$ $115)$ genotype [\%6-MP dose intensity: $82 \%(45-96)$ vs 90\% (27-100), $\mathrm{p}=0.034]$ (Figure 2C).

None of the other polymorphisms screened (TPMT*3C, ITPA c.94 C > A, and MRP4 c.2269 G>A) were significantly associated with 6-MP dose intensity. With respect to therapy intervention, patients who were heterozygous for NUDT15 c.415C $>$ T polymorphism had the maximum duration of cessation of 6-MP therapy compared to those who were wild type [23 (0-67) vs 14 (0-67) days, respectively, $\mathrm{p}=0.033$ ] in cohort-2 (Figure 2D).

In the multivariate analysis, there was no significant association between NUDT15 c. $415 \mathrm{C}>\mathrm{T}$ polymorphism and 6-MP dose reduction (Table 2). 


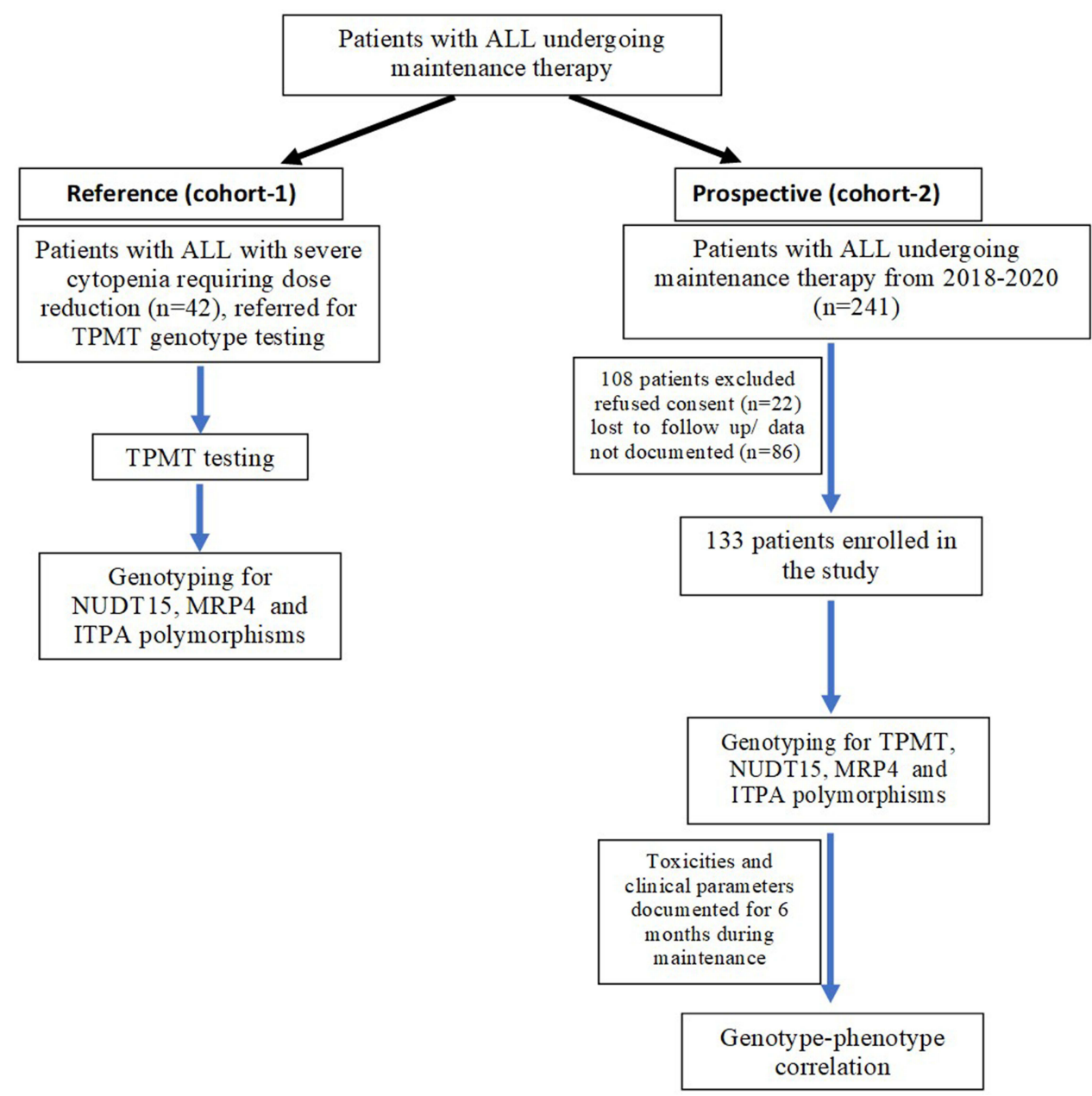

Figure I Study design.

\section{NUDT I5, ITPA, and TPMT Polymorphisms Explain Myelotoxicity but Not Hepatotoxicity}

We then evaluated the association between these polymorphisms and myelotoxicity, hepatotoxicity, relapse, and survival. In cohort-1, patients who were homozygous/heterozygous for NUDT15 c. $415 \mathrm{C}>\mathrm{T}$ polymorphism had significantly lower ANC [Median ANC-504 (321443) $\mathrm{mm}^{3}$ ] compared to patients with wild-type genotype [988 (280-1760) $\left.\mathrm{mm}^{3}, \mathrm{p}=0.006\right]$.

In cohort-2, patients who were heterozygous for NUDT15 c. $415 \mathrm{C}>\mathrm{T}$ polymorphism had significantly higher early (Median ANC: 507 vs $1298 \mathrm{~mm}^{3}$; $\mathrm{p}<0.0001$ ) and late myelotoxicity (Median ANC: 982 vs $1517 \mathrm{~mm}^{3} ; \mathrm{p}=0.015$ ) compared to patients carrying wild-type genotype (Figure 3). Additionally, ITPA c.94C $>$ A and TPMT*3C polymorphisms also contributed to myelotoxicity; patients who had risk allele for $T_{P M T}^{*} 3 \mathrm{C}$ and ITPA c.94C $>$ A polymorphism had significantly lower ANC (Median ANC: 376 vs $1014 \mathrm{~mm}^{3}$; $\mathrm{p}=0.04$ and 776 vs $1023 \mathrm{~mm}^{3}$; $\mathrm{p}=0.04$ respectively) during maintenance therapy (Figure S1). Upon multivariate analysis (cohort-2), although NUDT15 c. 415C $>\mathrm{T}$, and TPMT*3C $(\beta=$ $-0.209, \mathrm{p}=0.02$ ) were significantly associated with myelotoxicity, NUDT15 c. $415 \mathrm{C}>\mathrm{T}$ was the most significant variable associated with both early $(\beta=-0.314, \mathrm{p}<0.0001)$ and late myelotoxicity $(\beta=-0.197, p=0.018)$ (Table 2$)$. None of the polymorphisms tested, including NUDT15, was associated with hepatotoxicity, relapse (RFS), and survival (OS \& EFS) (Figure S2).

Interestingly, a significant proportion of patients (10 of the 36 patients with severe myelotoxicity in cohort 2 (28\%)) carried no variants for any of the screened polymorphisms but still had severe neutropenia [Median ANC$\left.214\left(88-420 \mathrm{~mm}^{3}\right)\right]$. Also, $53 \%$ of patients $(\mathrm{n}=21)$ who received $\leq 80 \%$ of the planned dose of 6-MP [Median \% 6-MP intensity-67 (45-79)] did not bear any genetic polymorphisms. 

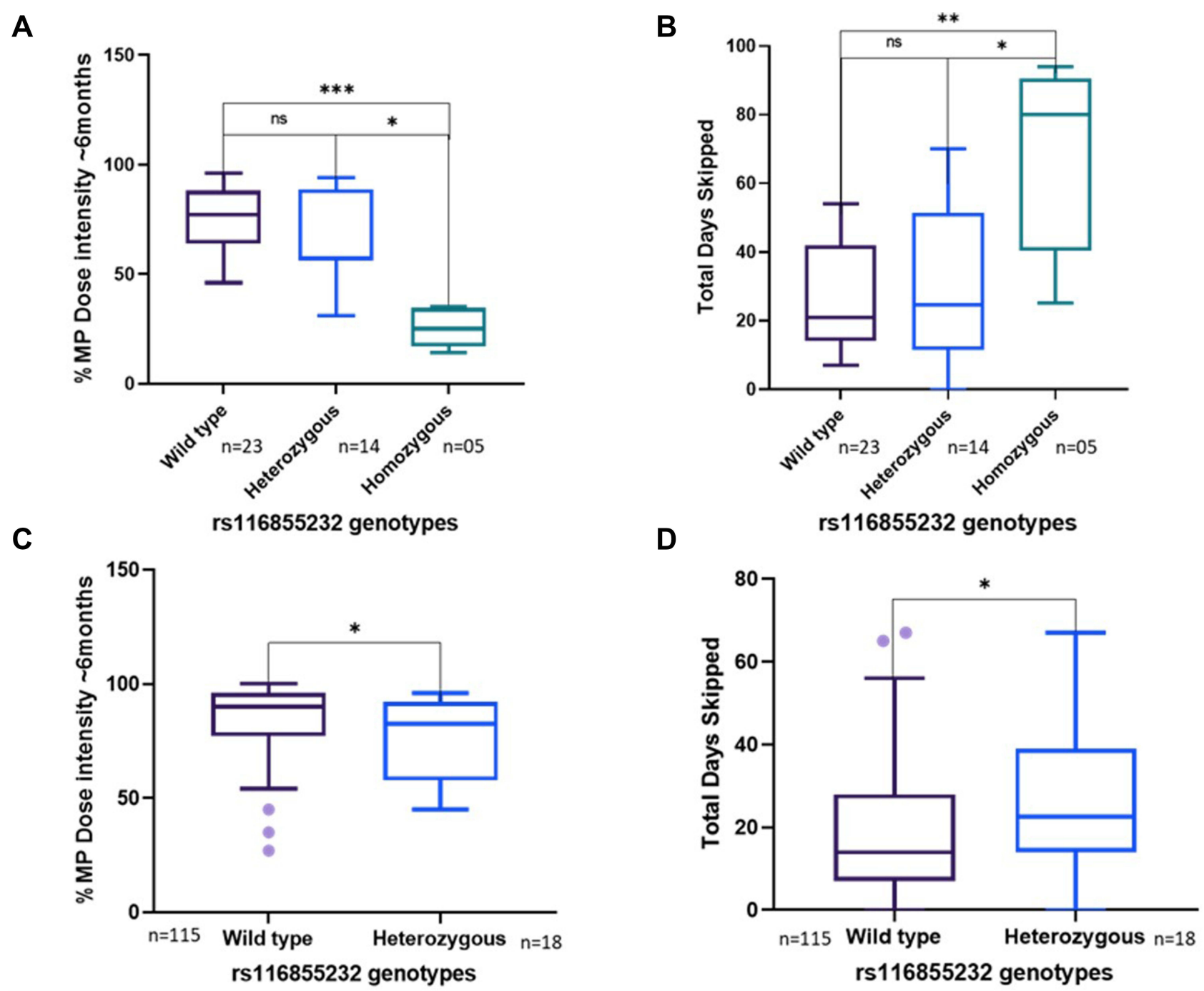

Figure 2 Associations between NUDTI5 c.4I5C>T polymorphism (rs I I6855232) and \% 6-MP dose intensity (A) and therapy interruption (B) in cohort-I and cohort-2 (C) and (D). *Asterisks indicate the level of the significance ( $p$-value); *Means $p<0.05$, **Means $p<0.01$, ***Means $p<0.001$ and ns-not significant.

\section{Combined Effect of Genotypes on 6-MP Intolerance and Toxicities}

To evaluate the combined effects of TPMT, NUDT15, $I T P A$, and MRP4 variants on 6-MP intolerance and toxicities, the patients in cohort- 2 with different genotype combinations were grouped-

Group 1- patients wild type for NUDT15, TPMT, ITPA, and MRP4 $(\mathrm{n}=66)$;

Group 2- patients with $M R P 4$ c.2269G $>$ A alone $(\mathrm{n}=11)$;

Group 3- patients with ITPA c.94 C > A alone $(\mathrm{n}=21)$ and

Group 4- patients with NUDT15 c.415C $>$ T alone $(\mathrm{n}=12)$.

Patients carrying the risk allele for NUDT15 c. $415 \mathrm{C}>\mathrm{T}$ polymorphism alone (Group 4) had increased myelotoxicity (OR-7.33; 95\% CI-0.72-3.33; $\mathrm{p}=0.002$ ) compared to Group 1. Similarly, patients harboring the risk allele for ITPA c.94 C > A polymorphism alone (Group 3) also had increased myelotoxicity (OR-3.49; 95\% CI-0.12-2.31; $\mathrm{p}=0.030$ ) compared to patients in Group 1 .

\section{Cost Analysis}

We then compared the total direct hospital costs incurred during the first 6 months of maintenance therapy between patients with wild-type genotype and those with heterozygous or homozygous for NUDT15 c. $415 \mathrm{C}>\mathrm{T}$ polymorphism among all patients (Cohort-1 + Cohort-2). The median total direct hospital cost incurred during the first 6 months of maintenance therapy was higher for patients with heterozygous or homozygous compared to patients with wild-type genotype for NUDT15 c.415C >T polymorphism [20245 (IQR: 12192 to 28746 INR) vs 14356 (IQR: 9939 to 19894 INR), $\mathrm{p}=0.07]$ 
Table 2 Association Analysis of Genetic Variants and Clinical Response in Prospective Patients with ALL Undergoing Maintenance Therapy

\begin{tabular}{|l|c|c|c|c|}
\hline $\begin{array}{l}\text { Clinical Responsel } \\
\text { Toxicities }\end{array}$ & \multicolumn{3}{|c|}{ Association Analysis* } \\
\hline Covariates & \multicolumn{2}{|c|}{$\begin{array}{c}\text { Univariate } \\
\text { Linear } \\
\text { Regression }\end{array}$} & $\begin{array}{c}\text { Multivariate } \\
\text { Regression }\end{array}$ \\
\cline { 2 - 5 } & $\boldsymbol{\beta}$ & p value & $\boldsymbol{\beta}$ & $\mathbf{p}$ value \\
\hline \% MP Dose intensity & & & & \\
Age & -0.195 & 0.063 & -0.044 & 0.760 \\
ALL risk group & -0.228 & 0.027 & -0.169 & 0.134 \\
BSA & -0.191 & 0.028 & -0.166 & 0.265 \\
MRP4 c.2269G>A & -0.178 & 0.050 & -0.029 & 0.789 \\
NUDTI5 c.4I5C>T & -0.173 & 0.047 & 0.138 & 0.203 \\
ITPA c.94 C>A & 0.155 & 0.081 & 0.137 & 0.200 \\
\hline Myelotoxicity & & & & \\
Early & & & & \\
Age & 0.162 & 0.063 & -0.062 & 0.590 \\
BSA & $\mathbf{0 . 2 4 5}$ & $\mathbf{0 . 0 0 5}$ & $\mathbf{0 . 2 6 3}$ & $\mathbf{0 . 0 2 4}$ \\
NUDTI5 c.4I5C>T & $-\mathbf{0 . 3 2 8}$ & $<\mathbf{0 . 0 0 1}$ & $-\mathbf{0 . 3 1 4}$ & $<\mathbf{0 . 0 0 I}$ \\
Late & & & & \\
TPMT*3A & $-\mathbf{0 . 1 8 1}$ & $\mathbf{0 . 0 4 2}$ & $-\mathbf{0 . 2 0 9}$ & $\mathbf{0 . 0 2 5}$ \\
NUDTI5 c.4I5C>T & $-\mathbf{0 . 1 9 1}$ & $\mathbf{0 . 0 2 8}$ & $-\mathbf{0 . 1 9 7}$ & $\mathbf{0 . 0 1 8}$ \\
\hline
\end{tabular}

Notes: *Amongst covariates tested in both univariate and multivariate regression, only significant variables are listed above. Bold values denote statistical significance at the $p \leq 0.05$ level.

\section{Discussion}

The present CPIC guidelines ${ }^{6}$ recommend NUDT15 and TPMT testing in patients before thiopurine therapy to prevent dramatic myelotoxicity. The frequency of these genetic polymorphisms is noticeably lower in the Indian population than in other populations (Table S3). Therefore, we aimed to explore the role of additional genetic variants over and above CPIC recommended genetic variants. This is the first single centre study to explore the association between NUDT15 (c.415C > T), TPMT (G238C, G460A \& A719G), ITPA (c.94C>A), and MRP4 (2269 G>A) polymorphisms vs early and late myelotoxicity to 6-MP in Indian patients with ALL on final maintenance therapy.

Similar to previous reports from other Asian studies ${ }^{22}$ and ours, ${ }^{7}$ except for the rare occurrence of the $T P M T * 3 \mathrm{C}$ variant, other TPMT polymorphisms were not identified in this cohort. The frequency of the NUDT15 c.415T allele in the present study is similar to previous studies in India, ${ }^{15-}$ ${ }^{17}$ but higher than that of the West Asian population, ${ }^{23}$ and lower than East Asian population ${ }^{24-26}$ (Table S3).

Patients belonging to Asian ancestry with NUDT15 c. $415 \mathrm{C}>\mathrm{T}$ polymorphism have been shown to be poor metabolizers of 6-MP and may show intolerance to the drug. ${ }^{27}$ Patients homozygous for NUDT15 c. $415 \mathrm{C}>\mathrm{T}$ polymorphism in the present study tolerated $\sim 25 \%$ of the total planned 6-MP dose, which is higher than the previously reported studies ${ }^{4,5}$ and the current recommended CPIC guidelines on 6-MP dosing. ${ }^{4-6}$ This discrepancy in 6-MP dose intensity $\left(25 \%\right.$ in the present study vs $8 \%{ }^{4,5}$ as per previous reports) can be attributed to different treatment practices. Apart from the $N U D T 15 * 3$, we failed to identify additional polymorphisms in NUDT15 exon 1 that has been reported to play role in 6-MP intolerance. ${ }^{28,29}$ It is possible that additional confounding genetic/non-genetic factors could also contribute to increased tolerance,
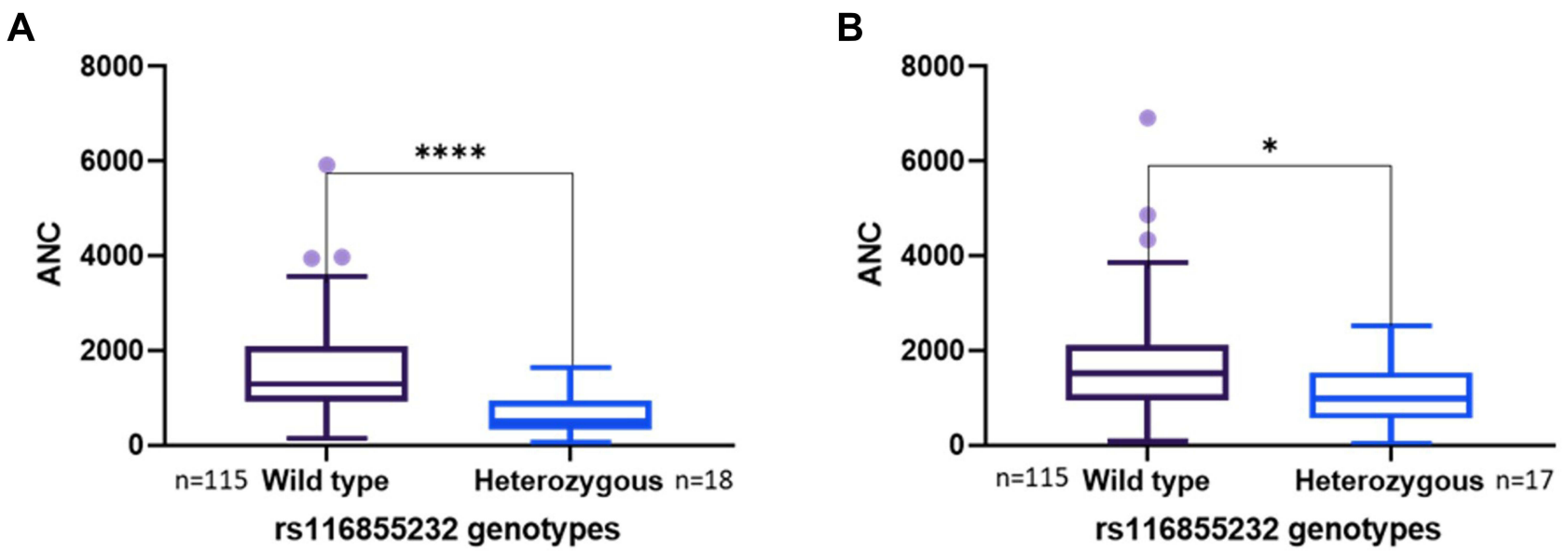

Figure 3 Associations between NUDTI5 c.4I5C>T polymorphism (rsI I6855232) and (A) Early, (B) Late Myelotoxicity. *Asterisks indicate the level of the significance (p-value); $*$ Means $p<0.05$ and $* * * *$ Means $p<0.000 \mathrm{I}$.

Abbreviation: ANC, absolute neutrophil count. 
especially in patients homozygous for NUDT15 c. $415 \mathrm{C}>\mathrm{T}$ polymorphism in the Indian population compared to other ethnicities, which needs to be further evaluated.

Myelotoxicity is a common adverse drug reaction during 6-MP maintenance therapy that may result in frequent febrile neutropenic episodes affecting treatment outcomes, risk of relapse, and quality of life. ${ }^{30}$ Similar to previous studies, ${ }^{15,25-27,31,32}$ patients who were homozygous for NUDT15 c.415C $>\mathrm{T}$ polymorphism experienced a significantly higher incidence of marrow toxicities and, as a result, experienced considerably more therapy interruptions/6-MP dose reduction in comparison to patients who were wild-type or heterozygous for this polymorphism (cohort-1). Although there were no patients with homozygous genotype for NUDT15 c. $415 \mathrm{C}>\mathrm{T}$ polymorphism in the prospective cohort, patients with heterozygous genotype experienced moderate/severe neutropenia leading to considerable dose reduction (Table 3). Although the TPMT polymorphisms were rare in our study cohort, patients who were heterozygous for $* 3 \mathrm{C}$ polymorphism experienced significantly increased neutropenic episodes similar to previous studies, ${ }^{33-35}$ but no significant 6-MP dose reduction.

ITPA is another crucial enzyme in thiopurine detoxification whose enzyme activity is genetically determined. ${ }^{11}$ A missense variant (c.94 C>A) was observed to be a significant determinant of mercaptopurine metabolism and severe febrile neutropenia. ${ }^{35-37}$ Consistent with previous reports, $9,10,22$ we observed that patients with variant genotype for ITPA c.94 C > A polymorphism experienced neutropenic episodes due to low ANC. Unlike previous studies $^{13,38}$ that showed ITPA c. $94 \mathrm{C}>\mathrm{A}$ polymorphism to be associated with lower EFS, we did not find this association in the present study.

A missense polymorphism (c.2269G $>$ A) identified in the MRP4/ATP binding cassette subfamily $\mathrm{C}$ member-4 $(A B C C 4)$ has been shown to dramatically enhance 6-MP sensitivity, especially in the Asian population. ${ }^{39}$ Tanaka et $\mathrm{al}^{10}$ have reported a high frequency of 6-MP dose reduction in Japanese children with ALL bearing homozygous variant allele for this polymorphism. These authors subsequently reported a higher incidence of leukopenia in children with risk allele for MRP4 c.2269G > A polymorphism but not with \%6-MP dose intensity. ${ }^{24}$ Similar to these reports, ${ }^{10,24}$ we observed that patients carrying risk allele for MRP4 c. $2269 \mathrm{G}>\mathrm{A}$ polymorphism experienced leukopenia (data not shown), albeit no 6-MP dose reduction. Our data suggest the limited clinical utility of MRP4 pharmacogenetics as compared to NUDT15 /TPMT in ALL.

In addition, we also identified a significant proportion of patients with severe neutropenia yet did not bear any genetic variants screened in this study, suggesting that additional genetic polymorphisms related/unrelated to the thiopurine metabolic pathway could explain 6-MP intolerance/toxicities. It is now well acknowledged that severe neutropenia can also be attributable to methotrexate intolerance $^{15,40}$ during maintenance therapy, which was not evaluated in the present study. An exploratory approach to identify additional genetic variants in patients who required dose reduction due to toxicities with no polymorphisms in NUDT15, ITPA, TPMT, or MRP4 genes is ongoing in our laboratory.

Table 3 Influence of NUDTI5 c.4I5C>T Polymorphism in Early 6-MP Induced Toxicities (Cohort-2)

\begin{tabular}{|c|c|c|c|}
\hline \multirow[t]{2}{*}{ Clinical Response } & \multicolumn{3}{|c|}{ Patients with NUDTI5 c.4I5C>T Polymorphism } \\
\hline & Wild Type, N=/I I5 (\%) & Heterozygous, $\mathrm{N}=/ / 8$ (\%) & Odds Ratio (95\% Cl), p-value* \\
\hline MP dose reduced $(<100 \%)$ & $99(86)$ & $18(100)$ & \multirow[t]{5}{*}{$1.6(-0.56-1.46), 0.36 \mathrm{I}$} \\
\hline \% MP Dose intensity & & & \\
\hline$>80 \%$ & $66(57)$ & II (6I) & \\
\hline $50-80 \%$ & $30(26)$ & $6(33)$ & \\
\hline$<50 \%$ & $3(3)$ & I (6) & \\
\hline Neutropenia (ANC <1500 mm m $^{3}$ & $84(73)$ & $18(100)$ & I 3.79 (0.57-7.48), 0.005 \\
\hline Severe neutropenia (ANC $<500 \mathrm{~mm}^{3}$ ) & $24(21)$ & $12(67)$ & $7.18(0.95-3.07), 0.000 \mathrm{I}$ \\
\hline Dose interruption & $98(85)$ & $17(94)$ & $2.07(-0.75-2.97), 0.373$ \\
\hline
\end{tabular}

Notes: *ORs and p-values were calculated using penalized likelihood test-Firth logistic regression method using R. Bold values denote statistical significance at the $p \leq 0.05$ level. 
Neutropenia and other thiopurine-induced toxicities culminate in increased cost of maintenance therapy. We observed that patients with heterozygous or homozygous NUDT15 c.415C $>$ T polymorphism had higher maintenance therapy-related costs. Therefore, pre-emptive genotype-based (NUDT15 c.415C $>$ T, TPMT) dosing could benefit Indian patients by decreasing the cost of maintenance therapy, minimizing hospital visits and therapeutic interventions.

The major limitation of the study is its retrospective nature, wherein none of the patients received tailored dosing based on genotype, including NUDT15 c.415C $>\mathrm{T}$ polymorphism. Other limitations include small sample size, wide window of the study period, and lack of validation cohorts. MTX is administered along with 6-MP, which also possesses similar myelotoxicity and hepatotoxicity. ${ }^{41}$ However, the present study did not address the role of MTX pharmacogenetics, which again is a major limitation.

\section{Conclusion}

Our results suggest that $N U D T 15 * 3, T P M T * 3 C$, as well as ITPA c. $94 \mathrm{C}>\mathrm{A}$ and MRP4 c.2269 $\mathrm{C}>\mathrm{T}$ polymorphisms explain hematological toxicity to 6-MP in patients with ALL undergoing maintenance therapy. Genotyping for NUDT15, TPMT, and ITPA is routinely performed in ALL patients undergoing maintenance therapy as well as in patients on thioguanine therapy for other conditions including AHA, ITP, inflammatory bowel disease (IBD), and autoimmune disorders at our centre. Preemptive genotype based (NUDT15*3, TPMT, ITPA c.94 C $>$ A) 6-MP dosing could improve the outcome after maintenance therapy. Further whole-genome sequencing in patients with severe myelotoxicity but not carrying TPMT or NUDT15 variants is ongoing to identify potential genetic risk for intolerance to maintenance therapy in ALL.

\section{Data Sharing Statement}

The datasets generated during and/or analyzed during the current study are available from the corresponding author on reasonable request.

\section{Ethical Approval}

Approval was obtained from the Institutional Review Board [IRB (EC)-ER-1-23-07-2014] of Christian Medical College, Vellore, India. The procedures used in this study adhere to the tenets of the Declaration of Helsinki.

\section{Informed Consent}

Informed consent was obtained from all individual participants/legal guardians included in the study.

\section{Acknowledgments}

We thank Dr Partha Majumdar (NIBMG, Kalyani) and Dr Ram Prasad (MedGenome Laboratories, Bengaluru) for providing the variant allele frequency data of the selected polymorphisms in the Indian population. Technical assistance provided by Ms Sangeetha is gratefully acknowledged. We thank all the medical and nursing staff who managed the outpatients.

\section{Author Contributions}

All authors contributed to data analysis, drafting, and revising the article, have agreed on the journal to which the article will be submitted, gave final approval of the version to be published, and agree to be accountable for all aspects of the work.

\section{Funding}

This study is funded by the Indian Council of Medical Research Centre for Advanced Research grant 70/14/14CAR to Dr Poonkuzhali Balasubramanian. AAP is supported by a Senior Research Fellowship from DBT, India. $\mathrm{VM}$ and $\mathrm{PB}$ are supported by Wellcome DBT India Alliance (IA/CPHS/18/1/503930 and IA/S/15/1/501842), respectively. UK is supported by an early career fellowship program of Wellcome DBT India Alliance (IA/CPHE/ 17/1/503351).

\section{Disclosure}

The authors report no conflicts of interest in this work.

\section{References}

1. Terwilliger T, Abdul-Hay M. Acute lymphoblastic leukemia: a comprehensive review and 2017 update. Blood Cancer J. 2017;7 (6):e577. doi:10.1038/bcj.2017.53

2. Relling MV, Hancock ML, Boyett JM, Pui CH, Evans WE. Prognostic importance of 6-mercaptopurine dose intensity in acute lymphoblastic leukemia. Blood. 1999;93(9):2817-2823.

3. Relling M, Gardner E, Sandborn W, et al. Clinical pharmacogenetics implementation consortium guidelines for thiopurine methyltransferase genotype and thiopurine dosing. Clin Pharmacol Ther. 2011;89 (3):387-391. doi:10.1038/clpt.2010.320

4. Yang JJ, Landier W, Yang W, et al. Inherited NUDT15 variant is a genetic determinant of mercaptopurine intolerance in children with acute lymphoblastic leukemia. J Clin Oncol. 2015;33(11):1235-1242. doi:10.1200/JCO.2014.59.4671

5. Moriyama T, Nishii R, Perez-Andreu V, et al. NUDT15 polymorphisms alter thiopurine metabolism and hematopoietic toxicity. Nat Genet. 2016;48(4):367-373. doi:10.1038/ng.3508 
6. Relling MV, Schwab M, Whirl-Carrillo M, et al. Clinical pharmacogenetics implementation consortium guideline for thiopurine dosing based on TPMT and NUDT15 genotypes: 2018 update. Clin Pharmacol Ther. 2019;105(5):1095-1105. doi:10.1002/cpt.1304

7. Desire S, Balasubramanian P, Bajel A, et al. Frequency of TPMT alleles in Indian patients with acute lymphatic leukemia and effect on the dose of 6-mercaptopurine. Med Oncol. 2010;27(4):1046-1049. doi:10.1007/s12032-009-9331-8

8. Illangeswaran RSS, Mohanan E, Nisham PN, et al. NUDT15 c. 415C >T variant explains 6-MP toxicity in patients with acute lymphoblastic leukemia, 57th Annual Conference of Indian Society of Haematology and Blood Transfusion 2016, Jaipur. Indian J Hematol Blood Transfus. 2016;32(2):373-492. doi:10.1007/s12288-016-0728-1

9. Ansari M, Sauty G, Labuda M, et al. Polymorphisms in multidrug resistance-associated protein gene 4 is associated with outcome in childhood acute lymphoblastic leukemia. Blood. 2009;114 (7):1383-1386. doi:10.1182/blood-2008-11-191098

10. Tanaka Y, Manabe A, Fukushima H, et al. Multidrug resistance protein 4 (MRP4) polymorphisms impact the 6-mercaptopurine dose tolerance during maintenance therapy in Japanese childhood acute lymphoblastic leukemia. Pharmacogenomics J. 2015;15 (4):380-384. doi:10.1038/tpj.2014.74

11. Stocco G, Cheok MH, Crews KR, et al. Genetic polymorphism of inosine triphosphate pyrophosphatase is a determinant of mercaptopurine metabolism and toxicity during treatment for acute lymphoblastic leukemia. Clin Pharmacol Ther. 2009;85(2):164-172. doi:10.1038/clpt.2008.154

12. Wan Rosalina WR, Teh LK, Mohamad N, et al. Polymorphism of ITPA $94 \mathrm{C}>\mathrm{A}$ and risk of adverse effects among patients with acute lymphoblastic leukaemia treated with 6-mercaptopurine. J Clin Pharm Ther. 2012;37(2):237-241. doi:10.1111/j.1365-2710.2011.01272.x

13. Kim H, Kang HJ, Kim HJ, et al. Pharmacogenetic analysis of pediatric patients with acute lymphoblastic leukemia: a possible association between survival rate and ITPA polymorphism. PLoS One. 2012;7(9):e45558. doi:10.1371/journal.pone.0045558

14. Devasia AJ, Illangeswaran RSS, Raj IX, George B, Balasubramanian P. NUDT15 polymorphism explains serious toxicity to azathioprine in Indian patients with chronic immune thrombocytopenia and autoimmune hemolytic anemia: a case series. Drug Metab Pers Ther. 2020. doi:10.1515/dmpt-2020-0128

15. Kodidela S, Dorababu P, Thakkar DN, et al. Association of NUDT15 c. $415 \mathrm{C}>\mathrm{T}$ and FPGS $2572 \mathrm{C}>\mathrm{T}$ variants with the risk of early hematologic toxicity during 6-MP and low-dose methotrexate-based maintenance therapy in Indian patients with acute lymphoblastic leukemia. Genes (Basel). 2020;11:6. doi:10.3390/genes11060594

16. Khera S, Trehan A, Bhatia P, Singh M, Bansal D, Varma N. Prevalence of TPMT, ITPA and NUDT 15 genetic polymorphisms and their relation to $6 \mathrm{MP}$ toxicity in north Indian children with acute lymphoblastic leukemia. Cancer Chemother Pharmacol. 2019;83 (2):341-348. doi:10.1007/s00280-018-3732-3

17. Shah SAV, Paradkar MU, Desai DC, Ashavaid TF. Preemptive NUDT15 genotyping: redefining the management of patients with thiopurine-induced toxicity. Drug Metab Pers Ther. 2018;33 (1):57-60. doi:10.1515/dmpt-2017-0038

18. Kojima Y, Hirotsu Y, Omata W, et al. Influence of NUDT15 variants on hematological pictures of patients with inflammatory bowel disease treated with thiopurines. World J Gastroenterol. 2018;24 (4):511-518. doi:10.3748/wjg.v24.i4.511

19. Common Terminology Criteria for Adverse Events (CTCAE). Protocol Development | CTEP. Available from: https://ctep.cancer. gov/protocolDevelopment/electronic_applications/ctc.htm\#ctc_60. Accessed October 13, 2020.

20. Moorman AV, Enshaei A, Schwab C, et al. A novel integrated cytogenetic and genomic classification refines risk stratification in pediatric acute lymphoblastic leukemia. Blood. 2014;124 (9):1434-1444. doi:10.1182/blood-2014-03-562918
21. Jain P, Korula A, Deshpande P, et al. Adult acute lymphoblastic leukemia: limitations of intensification of therapy in a developing country. JGO. 2018;4:1-12. doi:10.1200/JGO.17.00014

22. Kakuta Y, Kinouchi Y, Shimosegawa T. Pharmacogenetics of thiopurines for inflammatory bowel disease in East Asia: prospects for clinical application of NUDT15 genotyping. $J$ Gastroenterol. 2018;53(2):172-180. doi:10.1007/s00535-017-1416-0

23. Moradveisi B, Muwakkit S, Zamani F, Ghaderi E, Mohammadi E, Zgheib NKITPA. TPMT, and NUDT15 genetic polymorphisms predict 6-mercaptopurine toxicity in middle eastern children with acute lymphoblastic leukemia. Front Pharmacol. 2019;10. doi:10.3389/ fphar.2019.00916.

24. Tanaka Y, Kato M, Hasegawa D, et al. Susceptibility to 6-MP toxicity conferred by a NUDT15 variant in Japanese children with acute lymphoblastic leukaemia. $B r J$ Haematol. 2015;171(1):109-115. doi:10.1111/bjh. 13518

25. Yi ES, Choi YB, Choi R, et al. NUDT15 variants cause hematopoietic toxicity with low 6-TGN levels in children with acute lymphoblastic leukemia. Cancer Res Treat. 2018;50(3):872-882. doi:10.4143/crt.2017.283

26. Zhou H, Li L, Yang P, et al. Optimal predictor for 6-mercaptopurine intolerance in Chinese children with acute lymphoblastic leukemia: NUDT15, TPMT, or ITPA genetic variants? BMC Cancer. 2018;18. doi:10.1186/s12885-018-4398-2

27. Liu Y, Meng Y, Wang L, Liu Z, Li J, Dong W. Associations between the NUDT15 R139C polymorphism and susceptibility to thiopurine-induced leukopenia in Asians: a meta-analysis. Onco Targets Ther. 2018;11:8309-8317. doi:10.2147/OTT.S177007

28. Schaeffeler E, Jaeger SU, Klumpp V, et al. Impact of NUDT15 genetics on severe thiopurine-related hematotoxicity in patients with European ancestry. Genet Med. 2019;21(9):2145-2150. doi:10.1038/ s41436-019-0448-7

29. Yu C-H, Chang Y-H, Wang D-S, et al. Determination of NUDT15 variants by targeted sequencing can identify compound heterozygosity in pediatric acute lymphoblastic leukemia patients. Sci Rep. 2020;10(1):14400. doi:10.1038/s41598-020-71468-y

30. Bhatia S, Landier W, Hageman L, et al. Systemic exposure to thiopurines and risk of relapse in children with acute lymphoblastic leukemia: a children's oncology group study. JAMA Oncol. 2015;1 (3):287-295. doi:10.1001/jamaoncol.2015.0245

31. Puangpetch A, Tiyasirichokchai R, Pakakasama S, et al. NUDT15 genetic variants are related to thiopurine-induced neutropenia in Thai children with acute lymphoblastic leukemia. Pharmacogenomics. 2020;21(6):403-410. doi:10.2217/pgs-2019-0177

32. Yin D, Xia X, Zhang J, et al. Impact of NUDT15 polymorphisms on thiopurines-induced myelotoxicity and thiopurines tolerance dose. Oncotarget. 2017;8(8):13575-13585. doi:10.18632/oncotarget.14594

33. Ford LT, Berg JD. Thiopurine S-methyltransferase (TPMT) assessment prior to starting thiopurine drug treatment; a pharmacogenomic test whose time has come. J Clin Pathol. 2010;63(4):288-295. doi:10.1136/jcp.2009.069252

34. Higgs JE, Payne K, Roberts C, Newman WG. Are patients with intermediate TPMT activity at increased risk of myelosuppression when taking thiopurine medications? Pharmacogenomics. 2010;11 (2):177-188. doi:10.2217/pgs.09.155

35. Evans WE, Hon YY, Bomgaars L, et al. Preponderance of thiopurine S-methyltransferase deficiency and heterozygosity among patients intolerant to mercaptopurine or azathioprine. J Clin Oncol. 2001;19 (8):2293-2301. doi:10.1200/JCO.2001.19.8.2293

36. Sumi S, Marinaki AM, Arenas M, et al. Genetic basis of inosine triphosphate pyrophosphohydrolase deficiency. Hum Genet. 2002;111 (4-5):360-367. doi:10.1007/s00439-002-0798-z

37. Atanasova S, Shipkova M, Svinarov D, et al. Analysis of ITPA phenotype-genotype correlation in the Bulgarian population revealed a novel gene variant in exon 6. Ther Drug Monit. 2007;29(1):6-10. doi:10.1097/FTD.0b013e3180308554 
38. Smid A, Karas-Kuzelicki N, Milek M, Jazbec J, Mlinaric-Rascan I. Association of ITPA genotype with event-free survival and relapse rates in children with acute lymphoblastic leukemia undergoing maintenance therapy. PLoS One. 2014;9(10):e109551. doi:10.1371/ journal.pone.0109551

39. Krishnamurthy P, Schwab M, Takenaka K, et al. Transportermediated protection against thiopurine-induced hematopoietic toxicity. Cancer Res. 2008;68(13):4983-4989. doi:10.1158/00085472.CAN-07-6790
40. Taylor ZL, Vang J, Lopez-Lopez E, Oosterom N, Mikkelsen T, Ramsey LB. Systematic review of pharmacogenetic factors that influence high-dose methotrexate pharmacokinetics in pediatric malignancies. Cancers. 2021;13(11):2837. doi:10.3390/cancers13112837

41. Schmiegelow K, Nielsen SN, Frandsen TL, Nersting J. Mercaptopurine/ methotrexate maintenance therapy of childhood acute lymphoblastic leukemia: clinical facts and fiction. J Pediatr Hematol Oncol. 2014;36 (7):503-517. doi:10.1097/MPH.0000000000000206

\section{Publish your work in this journal}

Pharmacogenomics and Personalized Medicine is an international, peer-reviewed, open access journal characterizing the influence of genotype on pharmacology leading to the development of personalized treatment programs and individualized drug selection for improved safety, efficacy and sustainability. This journal is indexed on the American Chemical Society's Chemical Abstracts Service (CAS). The manuscript management system is completely online and includes a very quick and fair peer-review system, which is all easy to use. Visit http://www.dovepress.com/testimonials.php to read real quotes from published authors. 